\title{
Lack of preservation of higher brain function during hypoglycaemia in patients with intensively-treated IDDM
}

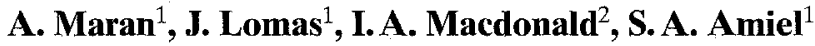 \\ ${ }^{1}$ Unit for Metabolic Medicine, United Medical and Dental Schools of Guy's and St Thomas' Hospitals, Guy's Campus, \\ London, UK \\ ${ }^{2}$ Department of Physiology and Pharmacology, Queen's Medical Centre, Nottingham University, Nottingham, UK
}

\begin{abstract}
Summary Severe hypoglycaemia with cognitive dysfunction is 3 times more common in intensively, rather than conventionally, treated insulin-dependent diabetes mellitus (IDDM). To investigate the effect of diabetes control on higher brain function during acute hypoglycaemia, we studied one of the earliest detectable changes in cognitive function, i.e. the four-choice reaction time, and symptomatic and hormonal responses during euglycaemic and hypoglycaemic clamping in human subjects. There were no changes in symptoms or counterregulatory hormones and four-choice reaction time was stable during 220 min of euglycaemic insulin clamping in five men with IDDM, with a coefficient of variation of less than $2.2 \%$ ( $1 \%$ for accuracy) for the cognitive function test. During stepped hypoglycaemic clamping however, hormonal responses and subjective awareness of hypoglycaemia occurred in all groups but started at much lower blood glucose concentrations in eight intensively-treated diabetic subjects
\end{abstract}

(Group 1) than in ten conventionally-treated (Group 2) or in eight non-diabetic subjects (Group 3). For example, for adrenaline, plasma glucose thresholds were $2.7 \pm 0.2$ vs $3.4 \pm 0.2$ and $3.2 \pm 0.1 \mathrm{mmol} / \mathrm{l}$, respectively, $p<0.05$, Group 1 vs Groups 2 or 3 and for subjective awareness of hypoglycaemia $2.3 \pm 0.2 \mathrm{vs}$ $3.0 \pm 0.1$ and $3.2 \pm 0.1 \mathrm{mmol} / \mathrm{l}, p \leq 0.003$ ), as in previous studies. In contrast, deterioration in reaction time occurred at $3.2 \pm 0.3,3.2 \pm 0.2$ and $3.0+0.2 \mathrm{mmol} / \mathrm{l}$, respectively ( $p=\mathrm{NS}$ ), thus occurring at higher glucose levels than subjective awareness in the intensively-treated subjects only. The altered hierarchy of responses to hypoglycaemia in well-controlled intensively-treated diabetes explains the increased risk of severe hypoglycaemia without warning seen in such patients. [Diabetologia (1995) 38: 1412-1418]

Key words Choice reaction time, cognitive function, hypoglycaemia, counterregulation, diabetes mellitus.
Intensified insulin therapy aims to maintain chronic near-normoglycaemia in patients with insulin-dependent diabetes mellitus (IDDM) and significantly reduces their risks of developing diabetic retinopathy, nephropathy and neuropathy $[1,2]$. However, the acceptability and wide-spread use of such therapy are limited by its association with a threefold increase in

Received: 13 January 1995 and in revised form: 24 May 1995

Corresponding author: Prof. S. A. Amiel, Department of Medicine, King's College School of Medicine and Dentistry, Bessemer Road, London SE5 9PJ, UK

Abbreviations: IDDM, Insulin-dependent diabetes mellitus. the incidence of both asymptomatic [3] and severe $[2,4]$ hypoglycaemia.

Some of the mechanisms underlying the defective responses to hypoglycaemia in intensified insulin therapy are now understood. Such therapy can induce defects in the usual symptomatic neurohumoral responses to experimentally-induced hypoglycaemia. These include a reduction in the magnitude of the hormonal response to any given hypoglycaemic stimulus $[5,6]$ and a lowering of the plasma glucose level at which each response begins $[6,7]$. It is suggested that the latter is due to an adaptation of the glucose sensing centres to preceding hypoglycaemia such that they are better able to maintain their metabolism and function during subsequent exposure to a 
Table 1. Clinical data for subjects

\begin{tabular}{|c|c|c|c|c|}
\hline & \multirow{2}{*}{$\begin{array}{l}\text { Study } \\
\text { one }\end{array}$} & \multicolumn{3}{|l|}{ Study two } \\
\hline & & Group One & Group Two & Group Three \\
\hline$n$ & 5 & 8 & 10 & 8 \\
\hline Male/female & $5 / 0$ & $6 / 2$ & $6 / 4$ & $5 / 3$ \\
\hline Age (years) & $33 \pm 4$ & $36 \pm 3$ & $32 \pm 4$ & $31 \pm 2$ \\
\hline $\begin{array}{l}\text { Diabetes dura- } \\
\text { tion (years) }\end{array}$ & $12 \pm 3$ & $16 \pm 2$ & $17 \pm 3$ & - \\
\hline $\mathrm{HbA}_{1}(\%)$ & $8 \pm 1$ & $.7 .7 \pm 0.3$ & $10.1 \pm 0.2$ & $<6$ \\
\hline
\end{tabular}

Data are mean \pm SD

low blood glucose level [8-10]. Because at least some of these centres are intra-cerebral [11, 12], one might expect other brain areas to undergo similar adaptation. If these include the cerebral cortex, cognitive function should also be better preserved during hypoglycaemia in hypoglycaemia-accustomed patients with delayed onset of counterregulation.

Although there are some experimental data to support this hypothesis $[13,14]$, there are also data that do not $[15,16]$. Furthermore, the hypothesis is not consistent with the clinical picture since intensively-treated diabetic patients with delayed subjective awareness of hypoglycaemia are not protected from severe episodes. One of the difficulties in investigating this issue is the lack of a sensitive and appropriate test for cognitive function that can be reliably applied repeatedly during induced hypoglycaemia. Electrophysiological measures are either too sensitive [17] or too crude [15] and summation of results from tests of multiple brain functions are also relatively insensitive [18].

To ascertain whether patients with intensivelytreated diabetes and hypoglycaemia unawareness have better preserved higher cerebral function during hypoglycaemia, we chose to use the "four choice reaction time" as a measure of cognitive function. This test measures the ability of a subject to perceive, interpret and make a co-ordinated response to a stimulus and as such measures a useful complex function $[19,20]$. This is also one of the functional tests most sensitive to hypoglycaemia. For our studies, we first validated repeated measurements over time during euglycaemia. We then measured symptomatic and neurohumoral responses and fourchoice reaction time during controlled insulin-induced hypoglycaemia in IDDM patients with strict glycaemic control and hypoglycaemia unawareness, those with poorly-controlled diabetes and good hypoglycaemia awareness, and in non-diabetic subjects.

\section{Subjects, materials and methods}

Study one. The study was approved by the Lewisham and North Southwark Committee on Ethical Practice. Written informed consent was obtained from each subject before enrol- ment. Five males with IDDM, aged $33 \pm 4$ years, diabetes duration $12 \pm 3$ years (Table 1 ) were admitted to the metabolic ward on the evening before the study. The subjects fasted from 22.30 hours onward. Two intravenous cannulae were placed using intradermal lignocaine as local anaesthetic, one for infusion of glucose and insulin into a large arm vein of the non-dominant hand, the other, for blood sampling, was placed retrogradely in a hand vein of the same arm. Subjects omitted their usual evening dose of intermediate or long-acting insulin and blood glucose was controlled through the night by means of an intravenous infusion of soluble insulin, adjusted according to hourly blood glucose measurements made at the bedside. All subjects therefore began the study in the morning with near-normal blood glucose concentrations and hypoglycaemia during the night was excluded.

In the morning, the hand carrying the sampling line was rested in a heated box $\left(55-60^{\circ} \mathrm{C}\right)$ to arterialize venous blood [21] and the subject was trained on the four-choice reaction time test $[19,20,22]$. In this test, the subject is presented with a computer screen divided into four quadrants. A computer-generated signal appears in one quadrant at a time and the subject has to clear it by pressing a corresponding button on an adapted keypad. Up to 500 signals are presented in $5 \mathrm{~min}$. The mean time of the reactions and the accuracy (the percentage of correct responses) are recorded. Training occurs over a maximum of five assessments and is recognised as stability in the timing and accuracy of the reaction.

At time $-40 \mathrm{~min}$, a primed continuous infusion of soluble insulin (prepared in a $4 \%$ solution of autologous blood in $0.9 \%$ saline) was started at a maintenance rate of $1.5 \mathrm{mU} \cdot \mathrm{kg}^{-1} \cdot \mathrm{min}^{-1}$ and run for $220 \mathrm{~min}$. Blood glucose was maintained at $5 \mathrm{mmol} / \mathrm{l}$ throughout by means of an infusion of $20 \%$ glucose, adjusted according to blood glucose measurements made at the bedside at 5- to 10-min intervals [23]. Every $20 \mathrm{~min}$, a full set of data was collected: blood samples for later measurement of the hormones of glucose counterregulation, measurement of the fourchoice reaction time and completion of symptom scores.

Symptom scores were recorded by questionnaires in which 52 symptoms were ranked individually from 0 (absent) to 6 (very severe). Adrenergic symptom scores were calculated from the scores of sweating, anxiety, trembling, tingling, heart pounding and feeling hot, neuroglycopenic symptom scores from the scores for inability to concentrate, confusion, dizziness, irritability, blurred vision, tiredness and drowsiness [24].

Study two. Subjects were recruited into three groups (Table 1). Group 1 comprised eight IDDM patients with tight metabolic control $\left(\mathrm{HbA}_{1 \mathrm{c}} 7.7 \pm 0.3 \%\right)$ and with a history of hypoglycaemia unawareness, substantiated by the occurrence of at least three blood glucose readings of less than $3 \mathrm{mmol} / 1$ without symptoms during 2 months of home blood glucose monitoring; Group 2 comprised ten patients with less well-controlled diabetes $\left(\mathrm{HbA}_{1 \mathrm{c}} 10.1 \pm 0.2 \%\right)$ and good hypoglycaemic awareness, and Group 3 were eight non-diabetic control subjects. For the subjects with diabetes, the number of severe hypoglycaemic episodes (i.e. those requiring external assistance) in the 4 months preceding the study had also been ascertained, with data collected every 2 weeks.

The diabetic subjects were rendered euglycaemic overnight as for Study One. The non-diabetic subjects presented in a fasted state on the morning of study. Once each subject had been cannulated and been trained on the equipment for measuring four-choice reaction time, the insulin and glucose infusions were begun as in Study One but for these subjects, euglycaemia was maintained for only $40 \mathrm{~min}$ ( -40 to $0 \mathrm{~min}$ ). Thereafter blood glucose was reduced step-wise over $220 \mathrm{~min}$ to a glucose nadir of $2 \mathrm{mmol} / \mathrm{l}$, after which euglycaemia was restored 

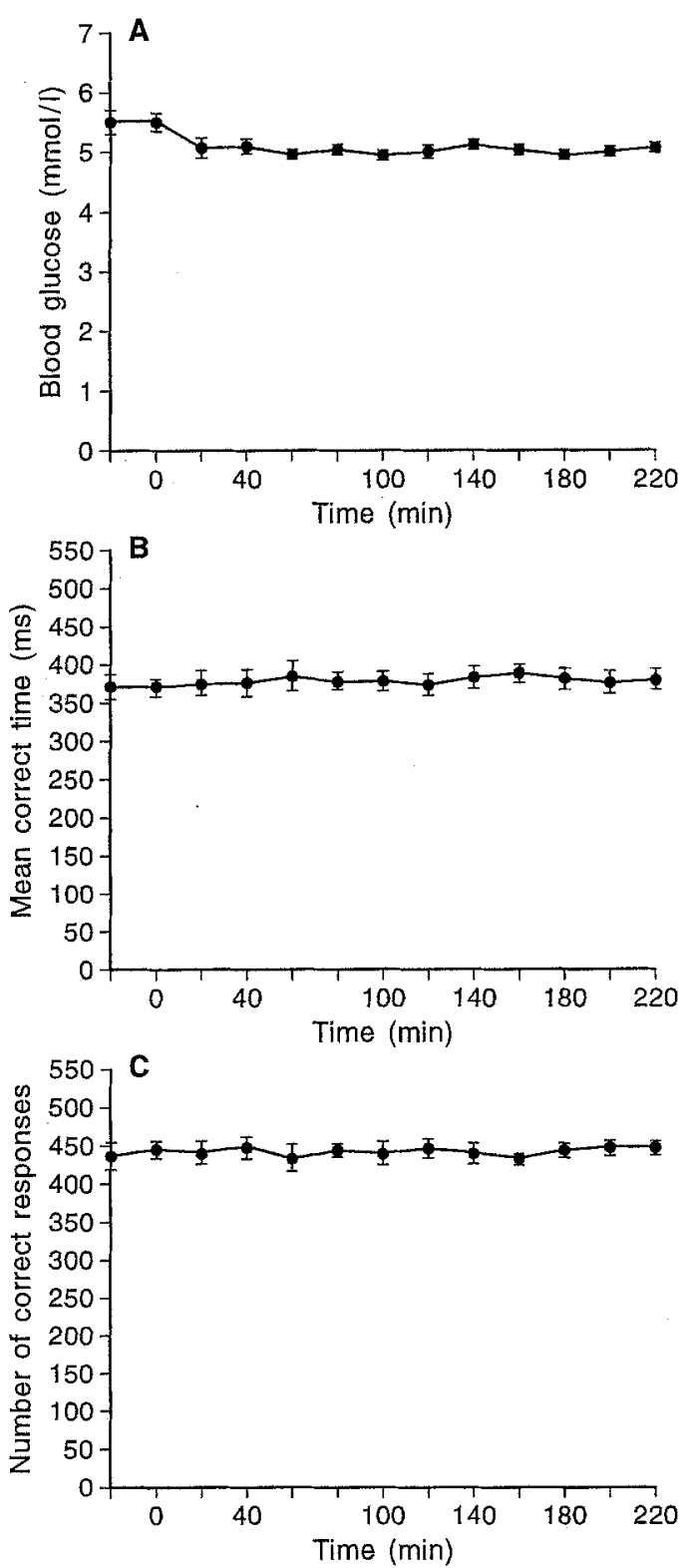

Fig.1A-C. Study one: cognitive function during euglycaemia. Blood glucose profiles (A), and the results of the four-choice reaction time $(\mathbf{B})$ and its accuracy $(\mathbf{C})$ during $220 \mathrm{~min}$ of euglycaemic clamping in five IDDM subjects

for a further $40 \mathrm{~min}$ [25]. Each glucose plateau was reached over 15 to $20 \mathrm{~min}$ and maintained for at least $20 \mathrm{~min}$, so that each step lasted $40 \mathrm{~min}$ in total, except the nadir, which was reached rapidly and held for a total of $20 \mathrm{~min}$. Hormone measurements were made at 20,30 and $40 \mathrm{~min}$ and symptom scores and four-choice reaction times recorded at 20 and 40 min into each plateau. In the non-diabetic subjects, euglycaemia was maintained from time 0 to $40 \mathrm{~min}$, the first hypoglycaemic step was to $3.8 \mathrm{mmol} / \mathrm{l}$ and hypoglycaemia was terminated at $2.6 \mathrm{mmol} / 1$, time $180 \mathrm{~min}$.

At the end of any study, subjects received lunch (and subcutaneous insulin if they were diabetic). Glucose monitoring was continued until stable euglycaemia was maintained spontaneously, after which all intravenous lines were withdrawn.

Measurements and calculations. Blood glucose was measured using a glucose oxidase method (Yellow Springs glucose ana-
A. Maran et al.: Cognitive dysfunction in acute hypoglycaemia

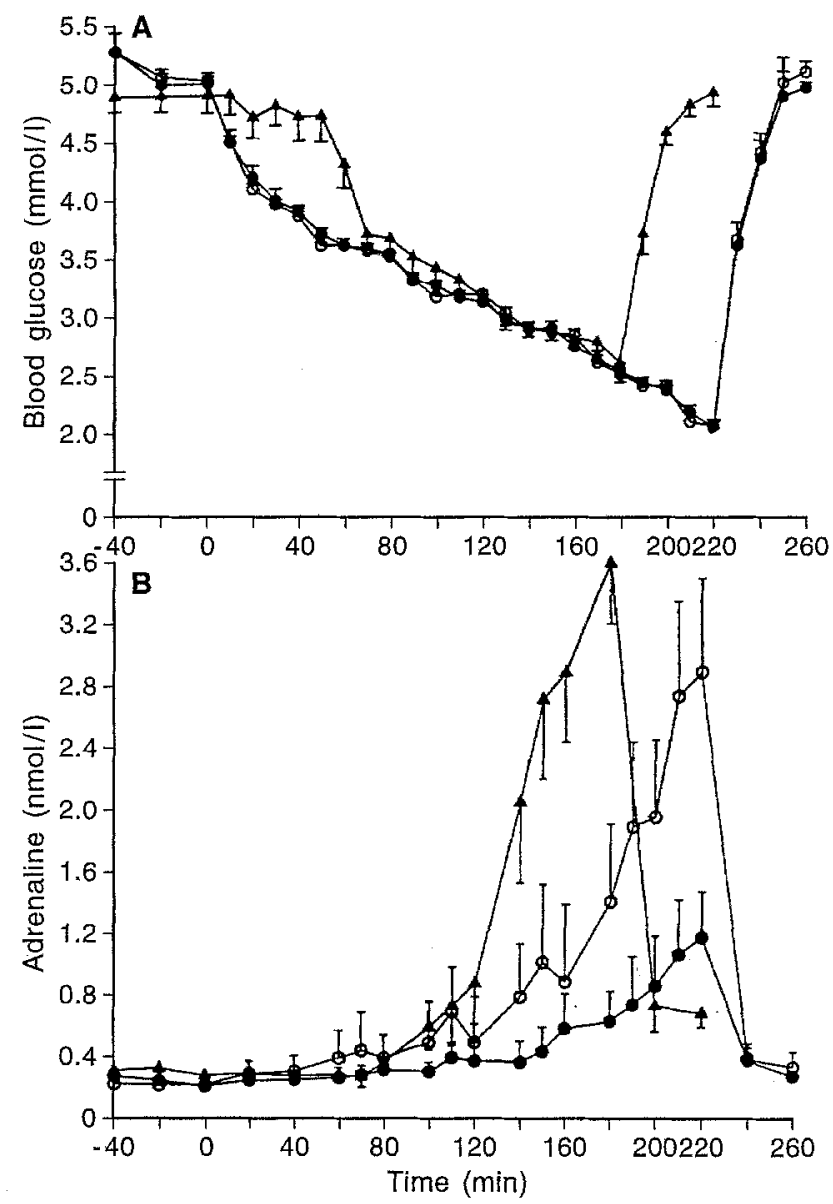

Fig. 2A, B. Study two: Hypoglycaemic clamps. Blood glucose profiles (A) and adrenaline responses (B) during hypoglycaemic clamping in subjects with well-controlled hypoglycaemia unaware $(O)$ and poorly-controlled $(O)$ and non-diabetic subjects $(\mathbf{A})$

lyzer, Yellow Springs Instruments, Yellow Springs, Ohio, USA). Catecholamines were measured by high performance liquid chromatography [26] and cortisol [27], growth hormone [28] and free insulin concentrations [29] were measured by radioimmunoassay. Intra-assay variation for any assay was less than $10 \%$. Thresholds for hormone responses were taken as the blood glucose level at which a given hormone concentration exceeded the mean of the five baseline (euglycaemic) levels by more than two standard deviations on two or more consecutive samples. A significant rise in symptom score was taken as a rise of two points or more over the score at euglycaemia, again on at least two successive occasions. After completion of Study One, a significant deterioration in reaction time was considered to have occurred when there were two or more consecutive increments of $5 \%$ or more and a loss of accuracy was defined as an increase of $2 \%$ or more in error rate, with the last measure made during euglycaemia as the baseline. If a significant change did not occur during hypoglycaemia, the glucose nadir was entered as the threshold for the statistical analyses.

\section{Statistical analysis}

Demographic data are given as mean \pm SD; all other data are given as mean \pm SEM. Hormone responses (area under curve) 
Table 2. Hormone responses to hypoglycaemia

\begin{tabular}{lcclll}
\hline Area under curve & & & & \\
& Group 1 & Group 2 & \multicolumn{2}{c}{ Group 3 } & $p$ value \\
\hline Noradrenaline & $198 \pm 27^{\mathrm{a}}$ & $264 \pm 11$ & NG & $<0.05$ \\
Growth hormone & $2286 \pm 386$ & $3412 \pm 435$ & - & 0.08 \\
Cortisol & $55674 \pm 6151$ & $76462 \pm 6963$ & - & 0.04 \\
Glucose levels at & which responses & began $(\mathrm{mmol} / \mathrm{l})$ & \\
Noradrenaline & $2.2 \pm 0.1^{\mathrm{a}}$ & $2.9 \pm 0.2$ & $3.3 \pm 0.2$ & 0.0003 \\
Growth hormone & $2.7 \pm 0.2$ & $3.1 \pm 0.1$ & - & 0.07 \\
Cortisol & $2.4 \pm 0.2$ & $2.9 \pm 0.1$ & - & 0.04 \\
\hline
\end{tabular}

Data given as mean \pm SEM

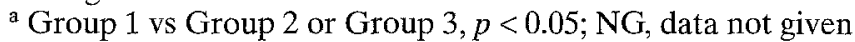
because of differences in glucose profiles

Table 3. Blood glucose concentrations (mmol/l) at onset of symptoms and cognitive dysfunction during hypoglycaemia

\begin{tabular}{lcccc}
\hline & Group 1 & Group 2 & Group 3 & $p$ value \\
\hline Symptoms & & & & \\
Autonomic & $2.4 \pm 0.1^{\mathrm{c}}$ & $2.8 \pm 0.1$ & $3.0 \pm 0.2$ & 0.025 \\
Neuroglycopenic & $2.3 \pm 0.2^{\mathrm{a}, \mathrm{b}}$ & $2.9 \pm 0.1$ & $3.2 \pm 0.2$ & 0.002 \\
Four-choice reaction time & & & \\
Reaction time & $2.9 \pm 0.3$ & $2.9 \pm 0.2$ & $2.9 \pm 0.4$ & 0.99 \\
Accuracy & $2.8 \pm 0.3$ & $3.0 \pm 0.3$ & $2.8 \pm 0.2$ & 0.82 \\
\hline
\end{tabular}

Data given as mean \pm SEM

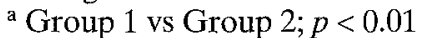

b Group 1 vs Group 3; $p<0.005$

${ }^{\mathrm{c}}$ Group 1 vs Group 3; $p<0.01$

and comparison of thresholds was made by one-way analysis of variance (ANOVA) and significance has been attributed to the groups by subsequent unpaired $t$-testing, except for growth hormone and cortisol data, available only for Groups One and Two, and so compared by unpaired $t$-testing alone.

\section{Results}

Study one. Blood glucose level was maintained at $5.1 \pm 0.04 \mathrm{mmol} / \mathrm{l}$ throughout, with a coefficient of variation of $4.6 \pm 1.3 \%$ (mean $\pm S D$ ). There were no significant changes in symptom scores (maximum individual score +1 ) or counterregulatory hormones. In the four-choice reaction time, the coefficient of variation for accuracy was $1 \%$ and for speed was $2.2 \%$ (Fig.1.). In Study Two, we therefore took a loss of accuracy of $2 \%$ and/or an increase in speed of $5 \%$ to indicate a significant deterioration in function.

Study two. Clinical monitoring before the clamp study in Groups 1 and 2 showed a similar frequency of mild hypoglycaemia in the preceding 2 months ( 4 to $23 \mathrm{ep}-$ isodes per patient in Group 1 vs $0-15$ in Group 2) but an increased frequency of severe hypoglycaemia in Group $1(0-4$ vs none, $p<0.04)$ in the preceding 4 months. Five of the Group 1 patients had experienced at least one severe hypoglycaemic episode within 6 months of the study.

The blood glucose profiles for the clamps are shown in Figure $2 \mathrm{~A}$. The hypoglycaemic profile was
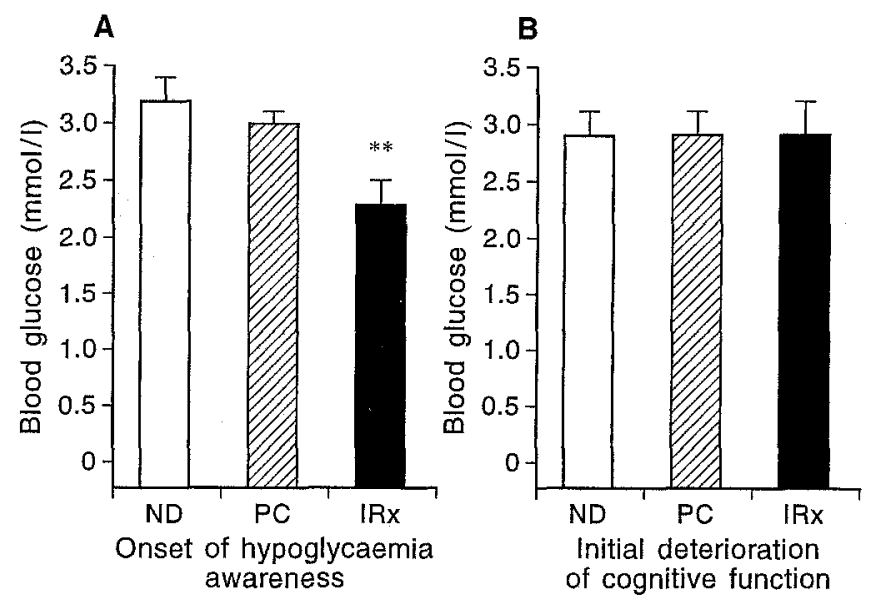

Fig. 3A, B. Study two: glucose thresholds for awareness of hypoglycaemia and cognitive dysfunction during acute hypoglycaemia. Blood glucose concentrations at onset of awareness of hypoglycaemia (A) and at initial deterioration of cognitive function (B) in subjects without diabetes (ND, $\square$ ) and in subjects with poorly controlled diabetes (PC, sively treated (IRx) hypoglycaemia unaware $(\square)$ diabetes. $* * p 0.0001$ )

identical for the two groups of IDDM subjects. In the non-diabetic subjects, the profile was distorted by the initial euglycaemic phase but the rate of glucose fall was not significantly different from 80 to $180 \mathrm{~min}(0.0094 \pm 0.0006,0.0099 \pm 0.0005$ and $0.0106 \pm 0.0007 \mathrm{mmol} / \mathrm{l}$ per $\mathrm{min}, p=0.23$ ).

As shown in Figure 2B, the magnitude of the adrenaline responses was significantly reduced in the well-controlled hypoglycaemia-unaware diabetic group. Peak responses were lowest in Group 1 $(1.28 \pm 0.26 \mathrm{nmol} / \mathrm{l})$, significantly greater in Group 2 $(2.63 \pm 0.24 \mathrm{nmol} / 1, p<0.05)$ and highest in Group 3 (3.7 $\pm 0.4 \mathrm{nmol} / \mathrm{l}, p<0.05$ against either of the other groups). The blood glucose concentration at which the adrenaline response began was significantly lower in Group 1 than in the other two groups $(2.7 \pm 0.2$ vs $3.4 \pm 0.2$ and $3.2 \pm 0.1 \mathrm{mmol} / 1, p=0.03$, Group 1 vs Group $2 p<0.02$; vs Group 3, $p<0.04)$. Similar reductions were observed in the magnitude of the responses of noradrenaline, growth hormone and cortisol, with lowering of the blood glucose levels associated with the onset of their responses, although for growth hormone the differences did not achieve significance (Table 2). Neither diabetic group had a glucagon response.

The blood glucose concentration at which subjects first became aware of hypoglycaemia (giving a positive answer to the question 'do you feel low?' or for non-diabetic subjects 'do you feel different?') was significantly lower in Group $1(2.3 \pm 0.2 \mathrm{mmol} / \mathrm{l})$ than in either Group $2(3.0 \pm 0.1, p=0.003)$ or Group 3 (3.2 $\pm 0.1, p=0.003$ vs Group 1 but 0.21 vs Group 2) (Fig. 3A). Autonomic and neuroglycopenic symptom scores also rose at significantly lower blood glucose concentrations in the hypoglycaemia- 
unaware patients in strict metabolic control (Group One) (Table 3). In marked contrast, there were no significant differences in the blood glucose concentrations at which deterioration in performance of the four-choice reaction time was first observed, whether reaction time itself or accuracy of performance (Table 3) or deterioration in either (Fig.3B) was considered. Only in Group One did cognitive function deteriorate before the onset of adrenaline or symptomatic responses (Fig. 2). It is of interest that baseline reaction times were not different between the groups $(473 \pm 30,437 \pm 18$ and $411 \pm 16 \mathrm{~min}$, one-way ANOVA $F=1.79, p=0.19$ ).

\section{Discussion}

Intensified insulin therapy, aimed at maintaining long-term near-normoglycaemia in patients with IDDM, can reduce the risk of developing microvascular complications by up to $76 \%$ [2]. However, such therapy has been associated with increased incidence both of loss of awareness of hypoglycaemia [3] and of severe hypoglycaemia, in which blood glucose falls so low that intellectual function and conscious level are impaired [2, 4]. The mechanism for this loss of awareness appears to be a lowering of the glucose level at which the symptomatic and hormonal responses to hypoglycaemia begin [6] and this is confirmed by our current data. In contrast, our data also show that the glucose level at which cognitive dysfunction first occurs is not lowered in such subjects. These data indicate a mechanism for both the asymptomatic hypoglycaemia and the increased risk of severe hypoglycaemia seen in patients on intensified insulin regimens, in whom the glucose level triggering symptomatic responses is significantly and uniquely lower than the glucose level at which cognitive dysfunction appears.

Although our findings are compatible with clinical experience of intensified insulin therapy, they may seem surprising in view of the evidence that both initiation of counterregulation and cognition are dependent upon brain metabolism. Onset of both can be delayed during hypoglycaemia by provision of physiological levels of non-glucose substrates for metabolism [30-32], and animal studies localise the site of initiation of counterregulatory responses to the brain $[11,12]$. In man, preceding hypoglycaemia can induce delayed and diminished symptomatic counterregulatory hormone responses to subsequent episodes acutely $[8,9]$ and cerebral glucose metabolic rate has been shown to be preserved during hypoglycaemia down to $2.4 \mathrm{mmol} / 1$ after $56 \mathrm{~h}$ of moderate hypoglycaemia in healthy volunteers [10]. It has been suggested that the defective counterregulatory responses of hypoglycaemia unaware diabetic patients may result from a chronic adaptation of cerebral glu- cose sensing areas to recurrent hypoglycaemia, as a result of which they better maintain metabolic rate and function during subsequent episodes [32,33].

Delayed onset of symptomatic and counterregulatory responses should therefore be associated with delayed onset of cognitive dysfunction. This is not supported by our present findings or by data from earlier studies using the relatively insensitive cortical electroencephalogram (EEG) as an objective measure of cortical function [15]. However, some evidence for this association exists. There are reports of a lowering of the blood glucose level at which the latency of the $\mathrm{P}_{300}$ evoked potential (a measure of cortical processing) increases during hypoglycaemia in hypoglycaemia-accustomed intensively treated diabetic patients [13] and Fanelli et al. [14] described some delay (although less than that seen for symptom generation) in the onset of cognitive dysfunction measured by a battery of tests during hypoglycaemia in patients with short-term hypoglycaemia-unaware intensively-treated diabetes. Boyle et al. [10] described lowering of the glucose level at which performance in Stroop tests and finger tapping changed in normal volunteers made hypoglycaemic after $56 \mathrm{~h}$ exposure to a blood glucose level of $2.8 \mathrm{mmol} / \mathrm{l}$. This is in direct contrast to our data.

One explanation for the discrepant results may be in the nature of the tests used to assess cognition. The $\mathrm{P}_{300}$ may be a very sensitive indicator of brain dysfunction, showing increased latency in one study (although not in others [34]) at plasma glucose levels of $4 \mathrm{mmol} / \mathrm{l}$, when there is no suggestion of clinically relevant cognitive impairment [35]. In contrast, a battery of cognitive function tests, applied at regular intervals during a hypoglycaemic challenge, may not be sufficiently specific, since the results of tests of several aspects of cortical function (some of which may be relatively insensitive to hypoglycaemia) are expressed as a single score. The battery method and indeed its component parts may also be relatively insensitive, changing in non-diabetic subjects at a glucose level of $2.4 \mathrm{mmol} / 1$, with detectable deterioration in performance of digit span at $2.4 \mathrm{mmol} / 1$, trail making at $2.3 \mathrm{mmol} / \mathrm{l}$ and symbol digit modalities at $2.6 \mathrm{mmol} / 1[33,36]$. When Widom and Simonson [9] compared the results of the elements of a cognitive function test battery individually, they found no effect of glycaemic control. The data from the Boyle study [10] are less readily compatible with ours, but the length and proximity of the antecedent hypoglycaemia may have produced a cortical effect not seen in response to the less stringent conditions of clinical diabetes treatment. Alternatively, different brain functions may be differentially affected. It is also possible that the tests are differently affected by catecholamines.

The four-choice reaction time, which requires signal perception and processing and the completion of a co-ordinated motor response, has been used to test 
higher brain function in such circumstances as recovery from anaesthesia [20]. We have shown it to be stable during repeated measurements at euglycaemia and it is not affected by catecholamines. It has the advantage of being quick to measure which is very important in studies of acute hypoglycaemia. As discussed above, our finding of a separation of effect of preceding glycaemic experience on cognition from that on counterregulatory responses may thus be due either to the increased sensitivity of the four-choice reaction time or to the fact that it is measuring a different aspect of cortical functioning from other tests.

The apparent inconsistency remaining between our data and those previously published is with the recent demonstration of preservation of cerebral glucose metabolism during hypoglycaemia in hypoglycaemia-accustomed healthy subjects [10]. This was an acute study in that measurements were made in healthy volunteers before and after $56 \mathrm{~h}$ of enforced moderate hypoglycaemia but it is likely to reflect the situation in hypoglycaemia accustomed IDDM patients. However, the arterio-venous difference technique used by Boyle et al. [10] to measure cerebral glucose utilisation rates measures glucose uptake by the whole intracranial contents. Our data would suggest that there is regional variation in the ease with which cerebral tissues can adapt to prior glycaemic experience to sustain their metabolism and function during subsequent hypoglycaemia. Such regional variation may also explain the apparent preservation of performance in Stroop testing and finger tapping seen in the study of Boyle et al. [10]. Confirmation of this requires more sophisticated techniques.

Heller and colleagues [37] first described a separation between the glucose levels required to trigger counterregulatory symptoms and adrenaline responses and those associated with cognitive dysfunction in individuals with diabetes. The new finding in the present data is the initial separation of subjects into those who are at high and those at low risk for severe hypoglycaemia and the subsequent demonstration of a different hierarchy of responses to acute hypoglycaemia.

Our findings have important clinical implications. It is the ability to make a co-ordinated response to stimuli that matters in human performance. Our data suggest that at least some higher brain functions cannot adapt to recurrent preceding hypoglycaemia. Lack of symptoms during biochemical hypoglycaemia should not therefore be interpreted to suggest that the cerebral cortex is functioning normally. We can find no evidence that intellectual function is better preserved during hypoglycaemia in intensivelytreated hypoglycaemia unaware patients. Intensified insulin therapy regimens should be tailored to avoid biochemical hypoglycaemia [38], no matter how well the individual patient appears to tolerate them.
Acknowledgements. This work was supported by funding from the Juvenile Diabetes Foundation International and the Leverhulme Trust, with additional support from Novo Nordisk Pharmaceuticals. We are very grateful to Mr. G. Chusney and Mr. D. Forster for their work in the laboratory, to Mr. A. Peacock for technical support and to Ms. Lucie Brunton and Debbie Smith for secretarial support.

\section{References}

1. Wan PH, Lau J, Chalmore TC (1993) Meta-analysis of effects of intensive blood glucose control on the development of the microvascular complications of type 1 diabetes. Lancet 341: 1306-1309

2. Diabetes Control and Complications Research Group (1993) The effect of intensive treatment of diabetes on the development and progression of long-term complications in insulin-dependent diabetes mellitus. N Engl J Med 329: 977-986

3. Lager I, Atvall S, Blohme G, Smith U (1986) Altered recognition of hypoglycaemic symptoms in type 1 diabetes during intensified control with continuous subcutaneous insulin infusion. Diabet Med 3: 322-325

4. Diabetes Control and Complications Research Group (1991) Epidemiology of severe hypoglycaemia in the Diabetes Control and Complications Trial. Am J Med 90: $450-459$

5. Simonson DC, Tamborlane WV, DeFronzo RA, Sherwin RS (1985) Intensive insulin therapy reduces the counterregulatory hormone responses to hypoglycaemia in patients with type 1 diabetes. Ann Intern Med 103: 184-190

6. Amiel SA, Sherwin RS, Simonson DC, Tamborlane WV (1988) Effect of intensive insulin therapy on glycemic thresholds for counterregulatory hormone release. Diabetes 37: 901-907

7. Amiel SA, Tamborlane WV, Simonson DC, Sherwin RS (1987) Defective glucose counterregulation after strict control of insulin-dependent diabetes mellitus. N Engl J Med 316: 1376-1383

8. Heller SR, Cryer PE (1991) Reduced neuroendocrine and symptomatic responses to subsequent hypoglycaemia in non-diabetic humans. Diabetes 40: 223-226

9. Widom B, Simonson DC (1990) Effect of intermittent hypoglycaemia on counterregulatory hormone secretion. Diabetologia 33[Supp1]:84 (Abstract)

10. Boyle PJ, Nagy RJ, O'Connor AM, Kempers SF, Yeo RA, Qualls C (1994) Adaptation in brain glucose uptake following recurrent hypoglycemia. Proc Natl Acad Sci 91: 93529356

11. Biggers DW, Myers SR, Neal D et al. (1989) Role of the brain in counterregulation of insulin induced hypoglycaemia in dogs. Diabetes 38: 7-16

12. Frizzell RT, Jones EM, Davis SN et al. (1993) Counterregulation during hypoglycaemia is directed by widespread brain organs. Diabetes 42: 1253-1261

13. Zeigler D, Hübinger A, Muhlen H, Gries FA (1992) Effects of previous glycaemic control on the onset and magnitude of cognitive dysfunction during hypoglycaemia in type 1 (insulin-dependent) diabetic patients. Diabetologia 35: 828-834

14. Fanelli CG, Epifano L, Rambotti AM et al. (1993) Meticulous prevention of hypoglycaemia normalizes the glycemic thresholds and magnitude of most of neuroendocrine responses to, symptoms of, and cognitive function during hypoglycaemia in intensively treated patients with shortterm IDDM. Diabetes 42: 1683-1689 
15. Amiel SA, Pottinger RC, Archibald HR et al. (1991) Effect of antecedent glucose control on cerebral function during hypoglycaemia. Diabetes Care 14: 109-118

16. Widom B, Simonson DC (1990) Glycaemic control and neurophysiologic function during hypoglycaemia in patients with insulin-dependent diabetes mellitus. Ann Intern Med 112: 904-912

17. DeFeo P, Gallai V, Mazzotta G et al. (1988) Modest decrements in plasma glucose concentration causes early impairment in cognitive function and later activation of glucose counterregulation in the absence of hypoglycaemic symptoms in normal man. J Clin Invest 82: 436-444

18. Mitrakou A, Fanelli C, Veneman T et al. (1993) Reversibility of unawareness of hypoglycaemia in patients with insulinomas. N Engl J Med 329: 834-839

19. Wilkinson RT, Houghton D (1975) Portable four-choice reaction time test with magnetic tape memory. Behav Res Meth Instrumentation 7: 441-446

20. Herbert M, Healy TEJ, Bourke JB, Fletcher IR, Rose JM (1983) Profile of recovery after general anaesthesia. BMJ 286: 1539-1542

21. Liu D, Moberg E, Kollind K, Lins P-E, Macdonald IA (1992) Arterial, arterialized venous, venous and capillary blood glucose measurements in normal man during hyperinsulinaemic euglycaemia and hypoglycaemia. Diabetologia 35: 287-290

22. Kerr D, Macdonald IA, Tattersall RB (1991) Patients with type 1 diabetes adapt acutely to sustained mild hypoglycaemia. Diabet Med 8: 123-128

23. DeFronzo RA, Tobin JD, Andres R (1979) Glucose clamp technique: a method for quantifying insulin secretion and resistance. Am J Physiol 237:E214-E223

24. Hepburn DA, Deary ID, Frier BM, Patrick AW, Quinn JD, Fisher BM (1991) Symptoms of acute insulin-induced hypoglycaemia in humans with and without IDDM. Factoranalysis based approach. Diabetes Care 14: 949-957

25. Amiel SA, Simonson DC, Tamborlane WV, DeFronzo RA, Sherwin RS (1987) Rate of glucose fall does not affect counterregulatory hormone responses to hypoglycaemia in normal and diabetic humans. Diabetes 36: 518-522

26. Macdonald IA, Lake DM (1985) An improved method for extracting catecholamines from body fluids. J Neurosci Meth 13: 239-248

27. Cunnah D, Jessop DS, Besser GM, Rees LH (1987) Measurement of corticotrophin releasing factor in man. J Endocrinol 113: 123-131
28. Mazlan M (1989) Development of an immunoradiometric assay for human growth hormone releasing factor and some applications. PhD thesis. University of London, London, UK

29. Hanning I, Home PD, Alberti KGMM (1985) Measurement of free insulin concentrations: the influence of the timing of extraction of insulin antibodies. Diabetologia 28: 831-835

30. Amiel SA, Archibald HR, Chusney G, Williams AJK, Gale EAM (1991) Ketone infusion lowers hormonal responses to hypoglycaemia: evidence for acute cerebral utilization of a non-glucose fuel. Clin Sci 81: 189-194

31. Maran A, Cranston I, Lomas J, Macdonald IA, Amiel SA (1994) Protection by lactate of cerebral function during hypoglycaemia. Lancet 343: 16-20

32. Veneman T, Mitrakou A, Mokan M, Cryer P, Gerich J (1994) Effect of hyperketonemia and hyperlacticacidemia on symptoms, cognitive dysfunction and counterregulatory hormone responses during hypoglycemia in normal humans. Diabetes 43: 1311-1317

33. Dagogo Jack S, Craft S, Cryer PE (1993) Hypoglycemia associated autonomic failure in insulin-dependent diabetes mellitus J Clin Invest 91: 819-828

34. Blackman JD, Towle VL, Lewis GF, Spire JP, Polonsky KS (1990) Hypoglycemic thresholds for cognitive dysfunction in humans. Diabetes 39: 825-828

35. DeFeo P, Gallai V, Mazzotta G, Bolli GB et al. (1988) Modest decrements in plasma glucose concentration cause early impairment in cognitive function and later activation of glucose counterregulation in the absence of hypoglycaemic symptoms in normal man. J Clin Invest 82: 436444

36. Mitrakou A, Ryan C, Veneman Tet al. (1991) Hierarchy of glycemic thresholds for counterregulatory hormone secretion, symptoms and cerebral dysfunction. Am J Physiol 260:E67-E74

37. Heller SR, Macdonald IA, Herbert M, Tattersall RB (1987) Influence of sympathetic nervous system on hypoglyaemic warning symptoms. Lancet II:359-363

38. Cranston I, Lomas J, Maran A, Macdonald IA, Amiel SA (1994) Restoration of hypoglycaemia awareness in patients with long-duration insulin-dependent diabetes. Lancet 344: $283-287$ 